\title{
Two Common MTHFR Gene Polymorphisms (C677T and A1298C) and Fetal Congenital Heart Disease Risk: An Updated Meta- Analysis with Trial Sequential Analysis
}

\author{
Rui Zhang ${ }^{a}$ Caihong Huo ${ }^{b}$ Xingning Wang ${ }^{a}$ Bo Dang \\ Yaning $\mathrm{Mu}^{\mathrm{d}}$ Yuying Wang ${ }^{\mathrm{d}}$
}

aDepartment of Clinical laboratory, The Affiliated Hospital of Yan'an University, Yan'an University, Yan'an, ${ }^{b}$ Department of Blood Transfusion, The 2nd Hospital of Yulin, Yulin City, 'Department of Neurology, The Traditional Chinese Medicine Hospital of Xi'an, Xi'an, dDepartment of Pediatrics, The Maternal and Children Health Hospital of Baoji, Baoji City, People's Republic of China

\section{Key Words}

MTHFR • Polymorphism • Fetal congenital heart disease risk • Meta-analysis

\begin{abstract}
Background/Aims: Published studies indicated that the MTHFR gene polymorphisms C677T and $\mathrm{A} 1298 \mathrm{C}$ are associated with congenital heart disease (CHD) risk in children, but obtained inconsistent results. Our study aims to reach a more accurate association between these two polymorphisms and CHD risk. Methods: Eligible studies were obtained by screening the PubMed, Embase, China National Knowledge Infrastructure, Wan Fang and VIP databases based on designed searching strategy. The odds ratio (OR) and 95\% confidence interval (CI) were calculated. Moreover, a trial sequential analysis was introduced to confirm the positive results and an RNA secondary structure analysis was also applied to discover the potential molecular mechanism. Results: Based on thirty-two published articles, involving 6988 congenital heart disease subjects and 7579 healthy controls, the pooled results from the C677T polymorphism in the fetal population showed increased risks in allelic model $(\mathrm{OR}=1.32,95 \% \mathrm{CI}=1.14-1.53)$, recessive model $(\mathrm{OR}=1.69,95 \% \mathrm{CI}=1.25-2.30)$, dominant model $(\mathrm{OR}=1.35,95 \% \mathrm{CI}=1.11$ 1.64), heterozygote model $(\mathrm{OR}=1.20,95 \% \mathrm{CI}=1.01-1.41)$ and homozygote model $(\mathrm{OR}=1.75$, $95 \% \mathrm{CI}=1.31-2.33)$. An increased risk was only detected in the A1298C polymorphism in the overall fetal popalation in a recessive model $(\mathrm{OR}=1.42,95 \% \mathrm{CI}=1.10-1.84)$. In the subgroup stratified by region, sample size, genotyping method and source of controls, the increased risks were widely observed in both the C677T and A1298C polymorphisms with CHD risk. Furthermore, trial sequential analysis confirmed our positive results, and the RNA secondary structure analysis detected the changes in the RNA secondary structure caused by the mutant $677 \mathrm{~T}$ allele and $1298 \mathrm{C}$ allele. Conclusion: In summary, we found that the MTHFR C677T polymorphism is associated with a significant increased risk in congenital heart disease

R. Zhang and C. Huo contributed equally to this work.

Bo Dang, Yaning Mu and Yuying Wang

Dept Neurology, The Traditional Chinese Medicine Hospiatl of Xi'an, Xi'an

Dept Pediatrics, The Maternal and Children Heath Hospital of Baoji, Baoji City (China) E-Mail XAZYDBO04@163.com, muyaning1969@126.com, wangyuying1964@163.com
\end{abstract}

KARGER 


\section{Cellular Physiology Cell Physiol Biochem 2018;45:2483-2496

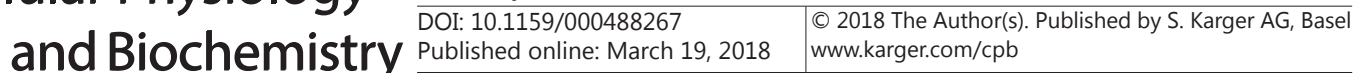

Zhang et al.: MTHFR C677T and A1298C Polymorphisms and Fetal Congenital Heart

Disease Risk

in the fetal population. Moreover, an increased risk in the CC genotype of MTHFR A1298C polymorphism was observed, but the protective role of the $1298 \mathrm{C}$ allele needs further study.

(C) 2018 The Author(s)

Published by S. Karger AG, Basel

\section{Introduction}

Congenital heart disease (CHD) is the most frequently occurring congenital disorder in newborns and the most common type of structural malformation of the heart and lager blood vessels $[1,2]$. The aetiology of CHD is unclear and CHD is multifactorial in its derivation. Different related genes interacting with each other or with environmental factors may contribute to development of CHD [3]. Folate plays a crucial role in the ontogeny of the cardiovascular system [4]. Insufficient folic acid and a high level of homocysteine (Hcy) caused by a defective folic acid pathway are described as risk factors for CHD [5]. Therefore, common polymorphisms of folate-metabolizing enzymes have gained great attention.

The MTHFR gene, located on 1p36.3, encodes the vital enzyme involved in the folate/ homocysteine metabolic pathway. Its transcription product is a $77 \mathrm{kDa}$ protein, that catalyses the reduction of 5, 10-methylenetetrahydrofolate to 5-methytetrahydrofolate, which as a methyl donor induces Hcy remethylation to methionine [6]. Two common functional polymorphisms in the MTHFR gene are widely studied. The first one is the MTHFR C677T mutation at exon 4, which results in the conversion of the amino acid alanine to valine at position 226 in the protein [6]. The other mutation (MTHFR A1298C) is located at exon 7, within the presumptive regulatory domain, and results in a glutamate-to-alanine change with decreased enzyme activity in vitro [7].

Associations between these two MTHFR gene polymorphisms and CHD risk were firstly analyzed by Wenstrom et al. [8]., more and more studies were conducted to perfect this work in the recent years. However, previous case-control reports or meta-analyses have drawn inconsistent results and many biases exist in these studies. Therefore, we performed an updated meta-analysis to investigate the associations between MTHFR polymorphisms (C677T and A1298C) and the susceptibility to CHD. Moreover, a trial sequential analysis and a RNA secondary structure analysis were introduced in our meta-analysis to confirm our positive results and identify the potential possible mechanism respectively.

\section{Materials and Methods}

Based on the PRISMA (Preferred Reporting Items for Systematic Reviews and Meta-analyses) checklist [9], we organized our update meta-analysis. Ethical approval was not necessary for the type of the study (meta-analysis) [10].

\section{Identification of related Studies}

A literature search was conducted by the first two investigators in the PubMed, Embase, China National Knowledge Infrastructure, Wan Fang and VIP databases before August 2017 without a language limitation. The terms "MTHFR," "methylenetetrahydrofolate reductase," "congenital heart disease," "CHD," "ventricular septal defect," "atrial septal defect," "tetralogy of Fallot," "patent ductus arteriosus," "polymorphism," "variant," "mutant," and "polymorphisms" were used. The data that we failed to retrieve during the electronic search were obtained by reviewing the citations or contacting the corresponding author of the potential eligible articles.

\section{Inclusion and Exclusion criteria}

The included studies needed to meet the following inclusion criteria: (1) studies of the association between the MTHFR gene polymorphisms and congenital heart disease; (2) case-control study or cohort design in fetal population; and (3) detailed genotype data could be acquired to calculate the odds ratios (ORs), and 95\% confidence intervals (CIs); The exclusion criteria were as follows: (1) duplication of previous publications; (2) comment, review and editorial; (3) study without detailed genotype data or 


\section{Cellular Physiology Cell Physiol Biochem 2018;45:2483-2496

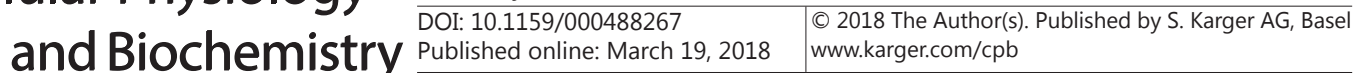

Zhang et al.: MTHFR C677T and A1298C Polymorphisms and Fetal Congenital Heart

Disease Risk

without a control group to conduct the Hardy-Weinberg equilibrium test; and (4) study departure from Hardy Weinberg equilibrium. The selection of the studies was achieved by two investigators independently. Any dispute was solved by a discussion with the corresponding author or group debates between all the authors.

\section{Data Extraction}

From each study, the following data were independently extracted by the first two investigators using a standardized form: first author's last name; year of publication; study country; region; genotyping methods; source of controls; number of cases and controls; genotype frequency in the cases and controls for the MTHFR gene; and results of the Hardy-Weinberg equilibrium test. Disagreements were resolved through a group discussion between authors.

\section{Statistical analysis}

The Hardy-Weinberg equilibrium (HWE) was evaluated for each study by a Chi-square test in the control group, and $\mathrm{P}<0.05$ was considered a significant departure from HWE. The odds ratio (OR) and 95\% confidence intervals (CIs) were calculated among five genetic models (allelic model (C677T: C versus T; A1298C: A versus C), recessive model (C677T: TT versus TC+CC; A1298C: CC versus CA+AA), dominant model (C677T: TT+TC versus CC; A1298C: CC+CA versus AA), heterozygote model (C677T: TC versus CC; A1298C: CA versus AA), and homozygote model (C677T: TT versus CC; A1298C: CC versus AA), respectively). Heterogeneity was evaluated by the $\mathrm{Q}$ statistic (significance level of $\mathrm{P}<0.1$ ) and $\mathrm{I}^{2}$ statistic (greater than $50 \%$ as evidence of significant inconsistency). A sensitivity analysis was performed to detect the heterogeneity by omitting one study in each turn. Additionally, subgroup analyses were stratified by region, sample size, genotyping method and source of controls. The publication bias was assessed with a Begg's funnel plot and an Egg's test. Review Manager, Version 5.3 (The Nordic Cochrane Centre, The Cochrane Collaboration; Copenhagen, Denmark) and STATA 12.0 (STATA Corp, LP) was used for all the analyses. Multiple comparisons were adjusted by the Bonferroni method and the false discovery rate (FDR) was calculated [11]. The statistically significant level was determined by a Z-test with P value less than 0.05 .

Trial sequential analysis (TSA)

TSA (The Copenhagen Trial Unit, Center for Clinical Intervention Research, Denmark) is a methodology that combines an information size calculation (cumulated sample sizes of all included trials) to reduce type I errors and type II errors for a meta-analysis with the threshold of statistical significance (http://www. ctu.dk/tsa). Therefore, we introduced TSA into our meta-analysis, and the required information size was calculated in adhere to an overall type I error of $5 \%$, a power of $90 \%$ and a relative risk reduction (RRR) assumption of $10 \%$.

\section{RNA secondary structure analysis}

The RNAfold WebServer is one of the core programs of the Vienna RNA package (http://rna.tbi.univie. ac.at/cgi-bin/RNAWebSuite/RNAfold.cgi) [12], which can be used to predict secondary structures of single stranded RNA or RNA sequences by computing the minimum free energy (MFE) of single sequences based on the dynamic programming algorithm originally proposed by Zuker and Stiegler [13]. Therefore, we input the RNA sequence of the MTHFR C677T and A1298C polymorphisms into the RNAfold WebServer to analyse the potential secondary structure modification caused by the mutant allele.

\section{Results}

\section{Characteristics of the Included Studies}

One hundred and fifty-one articles were obtained by the online and manual search. After removing duplicates, screening the title and abstract and reading the full-text articles, forty-two articles were included in the qualitative synthesis, and then, nine articles were excluded for departure from the Hardy Weinberg Equilibrium. Finally, a total of thirty-three published articles [4, 14-45] involving 6988 cases and 7579 controls, were included in this meta-analysis (Fig. 1). 
Zhang et al.: MTHFR C677T and A1298C Polymorphisms and Fetal Congenital Heart Disease Risk

The characteristics of all the included articles are summarized in Table 1. For the C677T variant, thirty-two studies are included with 4848 cases and 5524 controls, and twelve studies with 2140 cases and 2055 controls, were included for the A1298C variant.

Results of the meta-analysis of the associations between MTHFR polymorphisms and congenital heart disease risk.

Table 2 shows the pooled results of this meta-analysis and the heterogeneity of the MTHFR gene polymorphisms and congenital heart disease risk.

For the C677T polymorphism, significant associations were observed in all the genetic models in the overall population but with high heterogeneity as follows: $\mathrm{T}$ versus $\mathrm{C}(\mathrm{OR}=1.32,95 \% \mathrm{CI}=1.14-1.53$, $\mathrm{P}=0.0003)$; $\mathrm{TT}+\mathrm{TC}$ versus $\mathrm{CC}(\mathrm{OR}=1.35$, 95\%CI=1.11-1.64, $\mathrm{P}=0.002)$; TT VS TC+CC (OR=1.69, 95\%CI=1.25-2.30, $\mathrm{P}=0.000)$; $\mathrm{TC}$ VS CC $(\mathrm{OR}=1.20,95 \% \mathrm{CI}=1.01-1.41, \mathrm{P}=0.03)$; and TT VS CC $(\mathrm{OR}=1.75,95 \% \mathrm{CI}=1.31$ 2.33, $\mathrm{P}=0.000$ ) (Fig. 2). However, when an adjusted $\mathrm{p}$ value test was conducted, the heterozygote model (TC VS CC) was a false positive. In addition, for the A1298C polymorphism, a significant association was only found in the recessive genetic model in the overall population (CC versus $\mathrm{CA}+\mathrm{AA}$ : $\mathrm{OR}=1.42,95 \% \mathrm{CI}=1.10-1.84, \mathrm{P}=0.008$ ) (Fig. 3).

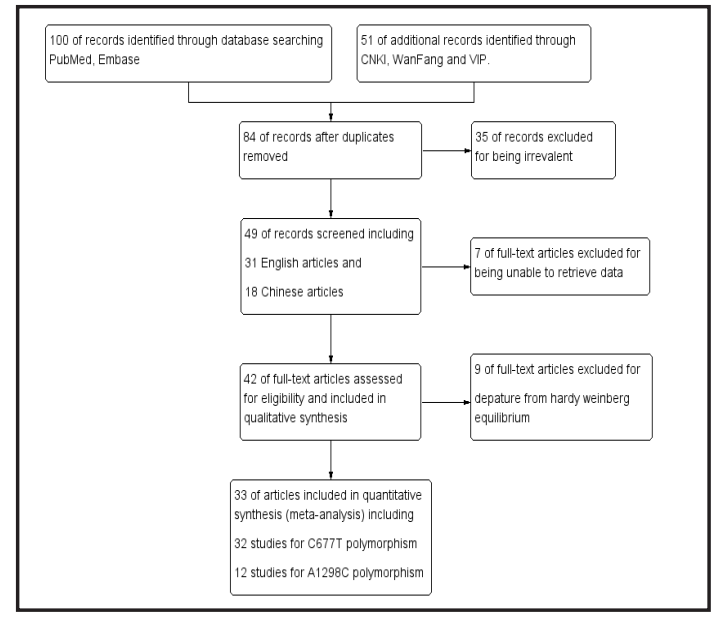

Fig. 1. Flowchart of literature search in our metaanalysis.

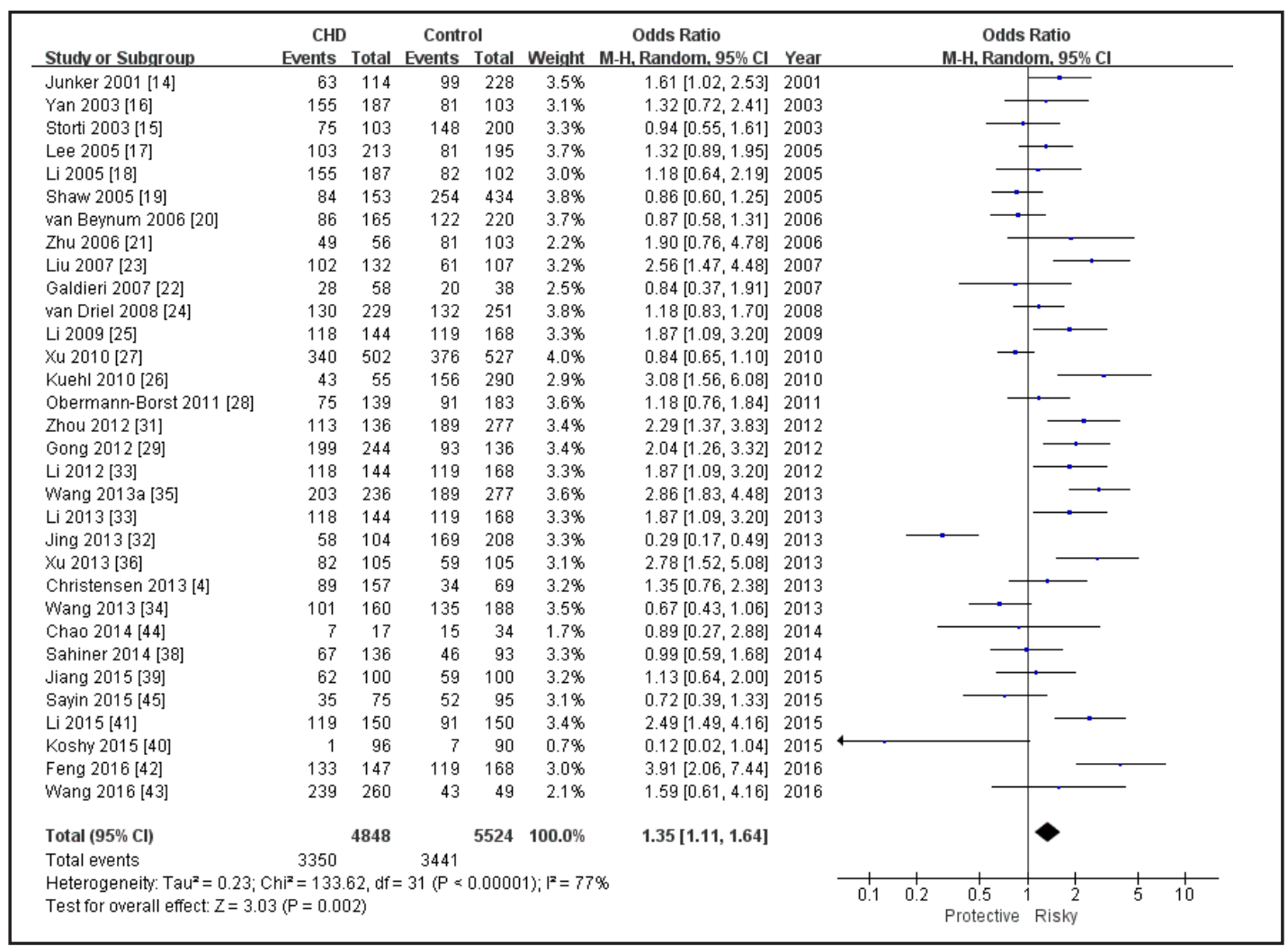

Fig. 2. Pooled analysis of C677T polymorphism and CHD risk in children population. 
Table 1. Characteristic of included studies of MTHFR C677T and A1298C polymorphisms associated with congenital heart disease. $\mathrm{HB}=$ Hospital Based; $\mathrm{PB}=$ Population Based; PCR-RFLP = polymerase chain reaction-restriction fragment length polymorphism; PCR-TAQMAN = polymerase chain reaction with Taqman probe. ; PCR-ABD = polymerase chain reaction using Assay by Design (ABD) kits from Applied Biosystems (Carlsbad, CA, USA): PCR-MassaArray Assay= Polymerase Chain Reaction with MassArray Assay. PCR-SSCP $=$ Polymerase Chain Reaction-Single Strand Conformation Polymorphism; PCR-SNaPShot $=$ polymerse chain reaction with SNaPShot; PCR-GeXP = Polymerse Chain Reaction with GeXP. HWE = Hardy-Weinberg equilibrium; * P value for Hardy-Weinberg equilibrium test in controls

\begin{tabular}{|c|c|c|c|c|c|c|c|c|c|c|c|c|c|c|}
\hline \multirow[b]{2}{*}{ First author } & \multirow[b]{2}{*}{ Year } & \multirow[b]{2}{*}{ Country } & \multirow[b]{2}{*}{ Region } & \multirow{2}{*}{$\begin{array}{l}\text { Genotyping } \\
\text { method }\end{array}$} & \multirow{2}{*}{$\begin{array}{c}\text { Controls } \\
\text { Source }\end{array}$} & \multirow[b]{2}{*}{ case } & \multirow[b]{2}{*}{ control } & \multirow[b]{2}{*}{ CC } & \multicolumn{2}{|l|}{ Case } & \multicolumn{3}{|c|}{ Control } & \multirow[b]{2}{*}{ HWE } \\
\hline & & & & & & & & & CT & TT & $\mathrm{CC}$ & СТ & TT & \\
\hline \multicolumn{15}{|c|}{ MTHFR C677T Polymorphism } \\
\hline Junker [14] & 2001 & Germany & Middle Europe & PCR-SSCP & HB & 114 & 228 & 51 & 42 & 21 & 129 & 78 & 21 & 0.075 \\
\hline Yan [16] & 2003 & China & East Asian & PCR-RFLP & $\mathrm{HB}$ & 187 & 103 & 32 & 97 & 58 & 22 & 57 & 24 & 0.277 \\
\hline Storti [15] & 2003 & Italy & South Europe & PCR-SSCP & HB & 103 & 200 & 28 & 55 & 20 & 52 & 108 & 40 & 0.235 \\
\hline Shaw [19] & 2005 & American & North America & PCR-TAQMAN & PB & 153 & 434 & 69 & 68 & 16 & 180 & 202 & 52 & 0.684 \\
\hline Li [18] & 2005 & China & East Asian & PCR-RFLP & HB & 187 & 102 & 32 & 94 & 61 & 20 & 57 & 25 & 0.224 \\
\hline Lee [17] & 2005 & China & East Asian & PCR-SSCP & HB & 213 & 195 & 110 & 89 & 14 & 114 & 68 & 13 & 0.513 \\
\hline Zhu [21] & 2006 & China & East Asian & PCR-RFLP & PB & 56 & 103 & 7 & 22 & 27 & 22 & 57 & 24 & 0.277 \\
\hline van Beynum [20] & 2006 & Netherlands & North Europe & PCR-SSCP & PB & 165 & 220 & 79 & 66 & 20 & 98 & 104 & 18 & 0.184 \\
\hline Liu [23] & 2007 & China & East Asian & PCR-RFLP & HB & 132 & 107 & 30 & 68 & 34 & 46 & 48 & 13 & 0.930 \\
\hline Galdieri [22] & 2007 & Brazil & South America & PCR-SSCP & HB & 58 & 38 & 30 & 21 & 7 & 18 & 14 & 6 & 0.263 \\
\hline van Driel [24] & 2008 & Netherlands & North Europe & PCR-TAQMAN & PB & 229 & 251 & 99 & 103 & 27 & 119 & 107 & 25 & 0.895 \\
\hline Li [25] & 2009 & China & East Asian & PCR-RFLP & HB & 144 & 168 & 26 & 52 & 66 & 49 & 84 & 35 & 0.928 \\
\hline Xu [27] & 2010 & China & East Asian & PCR-SSCP & $\mathrm{HB}$ & 502 & 527 & 162 & 244 & 96 & 151 & 261 & 115 & 0.911 \\
\hline Kuehl [26] & 2010 & American & North America & PCR-TAQMAN & $\mathrm{PB}$ & 55 & 290 & 12 & 33 & 10 & 134 & 124 & 32 & 0.682 \\
\hline Obermann-Borst [28] & 2011 & Netherlands & North Europe & PCR-TAQMAN & PB & 139 & 183 & 64 & 66 & 9 & 92 & 76 & 15 & 0.900 \\
\hline Zhou [31] & 2012 & China & East Asian & PCR-SSCP & HB & 136 & 277 & 23 & 60 & 53 & 88 & 126 & 63 & 0.168 \\
\hline Li [30] & 2012 & China & East Asian & PCR-RFLP & HB & 144 & 168 & 26 & 52 & 66 & 49 & 84 & 35 & 0.928 \\
\hline Gong [29] & 2012 & China & East Asian & PCR-MassArray Assay & HB & 244 & 136 & 45 & 123 & 76 & 43 & 72 & 21 & 0.309 \\
\hline Li [33] & 2013 & China & East Asian & PCR-RFLP & HB & 144 & 168 & 26 & 52 & 66 & 49 & 84 & 35 & 0.928 \\
\hline Jing [32] & 2013 & China & East Asian & PCR-RFLP & HB & 104 & 208 & 46 & 42 & 16 & 39 & 114 & 55 & 0.139 \\
\hline WangLN [35] & 2013 & China & East Asian & PCR-SSCP & HB & 236 & 277 & 33 & 92 & 111 & 88 & 126 & 63 & 0.168 \\
\hline WangBJ [34] & 2013 & China & East Asian & PCR-SNaPShot & HB & 160 & 188 & 59 & 76 & 25 & 53 & 100 & 35 & 0.312 \\
\hline Christensen [4] & 2013 & Canada & North America & PCR-RFLP & HB & 157 & 69 & 68 & 61 & 28 & 35 & 26 & 8 & 0.360 \\
\hline $\mathrm{Xu}[36]$ & 2013 & China & East Asian & PCR-SSCP & HB & 105 & 105 & 23 & 54 & 28 & 46 & 40 & 19 & 0.059 \\
\hline Sahiner [38] & 2014 & Turkey & West Asian & PCR-SSCP & HB & 136 & 93 & 69 & 53 & 14 & 47 & 39 & 7 & 0.779 \\
\hline Chao [44] & 2014 & China & East Asian & PCR-RFLP & HB & 17 & 34 & 10 & 5 & 2 & 19 & 12 & 3 & 0.586 \\
\hline Sayin [45] & 2015 & Turkey & West Asian & PCR-RFLP & HB & 75 & 95 & 40 & 33 & 2 & 43 & 44 & 8 & 0.484 \\
\hline Li [41] & 2015 & China & East Asian & PCR-SSCP & HB & 150 & 150 & 31 & 78 & 41 & 59 & 66 & 25 & 0.376 \\
\hline Koshy [40] & 2015 & Indian & South Asian & PCR-RFLP & HB & 96 & 90 & 95 & 1 & 0 & 83 & 7 & 0 & 0.701 \\
\hline Jiang [39] & 2015 & China & East Asian & PCR-RFLP & HB & 100 & 100 & 38 & 46 & 16 & 41 & 48 & 11 & 0.583 \\
\hline Feng [42] & 2016 & China & East Asian & PCR-GeXP & HB & 260 & 49 & 21 & 114 & 125 & 6 & 22 & 21 & 0.949 \\
\hline Wang [43] & 2016 & China & East Asian & PCR-RFLP & HB & 147 & 168 & 14 & 73 & 60 & 49 & 84 & 35 & 0.928 \\
\hline \multicolumn{15}{|c|}{ MTHFR A1298C Polymorphism } \\
\hline Storti [15] & 2003 & Italy & South Europe & PCR-SSCP & HB & 103 & 200 & 45 & 47 & 11 & 101 & 86 & 13 & 0.347 \\
\hline Galdieri [22] & 2007 & Brazil & South America & PCR-SSCP & HB & 57 & 38 & 35 & 21 & 1 & 19 & 16 & 3 & 0.884 \\
\hline van Driel [24] & 2008 & Netherlands & North Europe & PCR-TAQMAN & PB & 229 & 251 & 112 & 90 & 27 & 97 & 129 & 25 & 0.057 \\
\hline $\mathrm{Xu}[27]$ & 2010 & China & East Asian & PCR-SSCP & HB & 502 & 527 & 316 & 168 & 18 & 326 & 185 & 16 & 0.091 \\
\hline Obermann-Borst [28] & 2011 & Netherlands & North Europe & PCR-TAQMAN & $\mathrm{PB}$ & 139 & 183 & 69 & 57 & 13 & 75 & 90 & 18 & 0.227 \\
\hline WangBJ [34] & 2013 & China & East Asian & PCR-SNaPShot & HB & 170 & 188 & 115 & 45 & 10 & 133 & 47 & 8 & 0.155 \\
\hline Christensen [4] & 2013 & Canada & North America & PCR-RFLP & HB & 157 & 69 & 78 & 67 & 12 & 38 & 26 & 5 & 0.849 \\
\hline Sahiner [38] & 2014 & Turkey & West Asian & PCR-SSCP & HB & 137 & 93 & 45 & 68 & 24 & 31 & 54 & 8 & 0.223 \\
\hline Huang [37] & 2014 & China & East Asian & PCR-MassArray Assay & $\mathrm{HB}$ & 170 & 208 & 111 & 56 & 3 & 146 & 56 & 6 & 0.823 \\
\hline Sayin [45] & 2015 & Turkey & West Asian & PCR-RFLP & HB & 69 & 99 & 20 & 36 & 13 & 51 & 37 & 11 & 0.288 \\
\hline Li [41] & 2015 & China & East Asian & PCR-SSCP & $\mathrm{HB}$ & 150 & 150 & 114 & 36 & 0 & 131 & 19 & 0 & 0.408 \\
\hline Feng [42] & 2016 & China & East Asian & PCR-GeXP & $\mathrm{HB}$ & 257 & 49 & 194 & 51 & 12 & 35 & 14 & 0 & 0.243 \\
\hline
\end{tabular}


Zhang et al.: MTHFR C677T and A1298C Polymorphisms and Fetal Congenital Heart Disease Risk

Table 2. Pooled ORs and 95\%CIs of the relationship between MTHFR polymorphisms and congenital heart disease risk. $\mathrm{CI}=$ confidence interval.a $\mathrm{P}$ value for between-study heterogeneity based on $\mathrm{Q}$ test; Bon= $\mathrm{p}$ value in Bonferroni test; FDR= false discovery rate. Significant results are marked in bold

\begin{tabular}{|c|c|c|c|c|c|c|c|c|c|c|c|c|c|c|c|c|}
\hline \multirow[b]{2}{*}{ Subgroup } & \multirow[b]{2}{*}{$\mathrm{N}$} & \multicolumn{3}{|c|}{ Allelic genetic model } & \multicolumn{3}{|c|}{ Dominant genetic model } & \multicolumn{3}{|c|}{ Recessive genetic model } & \multicolumn{3}{|c|}{ Heterozygote genetic model } & \multicolumn{3}{|c|}{ Homozygote genetic model } \\
\hline & & $\mathrm{OR}[95 \% \mathrm{Cl}$ & $\mathrm{P}^{*}$ & 12 & OR[95\%Cl] & $\mathrm{P}^{*}$ & I2 & $\mathrm{OR}[95 \% \mathrm{CI}]$ & $\mathrm{P}^{*}$ & I2 & OR[95\%CI] & $\mathrm{P}^{*}$ & 12 & $\mathrm{OR}[95 \% \mathrm{CI}]$ & $\mathrm{P}^{*}$ & 12 \\
\hline \multicolumn{17}{|l|}{ MTHFR C677T } \\
\hline \multicolumn{17}{|l|}{ Region } \\
\hline Middle Europe & 1 & $1.63[1.16$ & 0.005 & $\mathrm{~N}$ & $1.61[1.02$, & 0.040 & $\mathrm{~N}$ & $1.23[0.63,2.38]$ & 0.550 & $\mathrm{~N}$ & $1.36[0.83$, & 0.220 & $\mathrm{~N}$ & $2.53[1.27$ & 0.008 & $\mathrm{~N}$ \\
\hline East Asian & 20 & $1.48[1.21$, & 0.000 & 87 & $1.55[1.17$ & 0.002 & 82 & $2.29[1.63,3.23]$ & 0.000 & 88 & $1.29[1.02$, & 0.030 & 70 & $2.10[1.43$, & 0.000 & 84 \\
\hline South Europe & 1 & $0.97[0.69$, & 0.840 & $\mathrm{~N}$ & $0.94[0.55$, & 0.820 & $\mathrm{~N}$ & $0.62[0.34,1.14]$ & 0.120 & $\mathrm{~N}$ & $0.95[0.54$ & 0.850 & $\mathrm{~N}$ & $0.93[0.46$ & 0.840 & $\mathrm{~N}$ \\
\hline North America & 3 & $1.30[0.81$, & 0.270 & 80 & $1.46[0.72$, & 0.290 & 81 & $0.81[0.17,3.83]$ & 0.790 & 92 & $1.40[0.71$, & 0.340 & 77 & $1.63[0.68$ & 0.280 & 72 \\
\hline South America & 1 & $0.83[0.45$ & 0.560 & $\mathrm{~N}$ & $0.84[0.37$ & 0.680 & $\mathrm{~N}$ & $1.33[0.42,4.21]$ & 0.630 & $\mathrm{~N}$ & $0.90[0.37$, & 0.820 & $\mathrm{~N}$ & $0.70[0.20$ & 0.570 & N \\
\hline North Europe & 3 & $1.08[0.91$, & 0.390 & 0 & $1.07[0.85$, & 0.540 & 0 & $1.08[0.73,1.60]$ & 0.690 & 0 & $1.04[0.79$, & 0.760 & 21 & $1.21[0.81$ & 0.350 & 0 \\
\hline West Asian & 2 & $0.89[0.60$, & 0.550 & 37 & $0.87[0.58$, & 0.480 & 0 & $0.83[0.10,6.95]$ & 0.870 & 81 & $0.87[0.58$, & 0.750 & 0 & $0.69[0.14$ & 0.640 & 65 \\
\hline South Asian & 1 & $0.13[0.02$, & 0.060 & $\mathrm{~N}$ & $0.12[0.02$, & 0.050 & $\mathrm{~N}$ & Not estimable & NA & $\mathrm{N}$ & $0.12[0.02$, & 0.050 & N & Not estimable & NA & $\mathrm{N}$ \\
\hline \multicolumn{17}{|l|}{ Sample Size } \\
\hline$\leq 300$ & 13 & $1.32[1.08$, & 0.006 & 59 & $1.35[1.01$, & 0.040 & 58 & $2.41[1.81,3.21]$ & 0.000 & 40 & $1.24[0.95$, & 0.110 & 47 & $1.91[1.36$ & 0.000 & 38 \\
\hline$>300$ & 19 & $1.34[1.10$, & 0.004 & 88 & $1.36[1.06$, & 0.020 & 83 & $1.49[0.98,2.26]$ & 0.070 & 92 & $1.18[0.96$, & 0.130 & 70 & $1.73[1.17$ & 0.006 & 86 \\
\hline \multicolumn{17}{|l|}{ Genotyping } \\
\hline PCR-RFLP & 14 & $1.36[1.03$, & 0.030 & 85 & $1.20[0.84$, & 0.300 & 75 & $2.26[1.51,3.39]$ & 0.000 & 80 & $1.07[0.77$, & 0.690 & 67 & $1.95[1.16$ & 0.010 & 81 \\
\hline PCR-SSCP & 11 & $1.34[1.06$, & 0.020 & 85 & $1.25[0.94$ & 0.120 & 75 & $1.48[1.07,2.06]$ & 0.020 & 72 & $1.18[0.91$, & 0.210 & 65 & $1.77[1.13$ & 0.010 & 81 \\
\hline PCR-TAQMAN & 4 & $1.17[0.88$ & 0.270 & 69 & $1.29[0.85$, & 0.230 & 71 & $0.58[0.30,1.10]$ & 0.100 & 71 & $1.29[0.86$, & 0.210 & 66 & $1.27[0.71$ & 0.420 & 59 \\
\hline PCR-MassArray & 1 & $1.79[1.33$, & 0.000 & $\mathrm{~N}$ & $2.04[1.26$ & 0.004 & $\mathrm{~N}$ & $5.26[3.12,8.86]$ & 0.000 & $\mathrm{~N}$ & $1.63[0.98$, & 0.060 & $\mathrm{~N}$ & $3.46[1.83$ & 0.000 & $\mathrm{~N}$ \\
\hline PCR-SNaPShot & 1 & $0.79[0.58$, & 0.120 & $\mathrm{~N}$ & $2.86[1.83$, & 0.000 & $\mathrm{~N}$ & $0.85[0.48,1.49]$ & 0.560 & $\mathrm{~N}$ & $1.95[1.20$ & 0.007 & $\mathrm{~N}$ & $0.64[0.34$, & 0.170 & $\mathrm{~N}$ \\
\hline PCR-GeXP & 1 & $1.24[0.79$, & 0.360 & $\mathrm{~N}$ & $3.91[2.06$, & 0.000 & $\mathrm{~N}$ & $11.46[6.91$ & 0.000 & $\mathrm{~N}$ & $1.48[0.54$, & 0.450 & $\mathrm{~N}$ & $1.70[0.61$ & 0.310 & $\mathrm{~N}$ \\
\hline \multicolumn{17}{|l|}{ Source of } \\
\hline PB & 6 & $1.22[0.96$, & 0.100 & 68 & $1.22[0.89$, & 0.210 & 62 & $0.82[0.45,1.49]$ & 0.510 & 78 & $1.15[0.85$, & 0.370 & 57 & $1.46[0.92$ & 0.110 & 55 \\
\hline HB & 26 & 1.34 [1.12, & 0.001 & 85 & $1.37[1.08$, & 0.009 & 79 & $2.03[1.47,2.80]$ & 0.000 & 87 & $1.20[0.99$, & 0.070 & 65 & $1.81[1.29$ & 0.000 & 82 \\
\hline
\end{tabular}

\begin{tabular}{|c|c|c|c|c|c|c|c|c|c|c|c|c|c|c|c|c|}
\hline \multicolumn{17}{|l|}{ Region } \\
\hline South Europe & 1 & $1.30[0.90$ & 0.160 & $\mathrm{~N}$ & $1.31[0.82$, & 0.260 & $\mathrm{~N}$ & $0.95[0.40,2.22]$ & 0.900 & $\mathrm{~N}$ & $1.23[0.74$, & 0.420 & $\mathrm{~N}$ & $1.90[0.79$, & 0.150 & $\mathrm{~N}$ \\
\hline South America & 1 & $0.62[0.32$ & 0.170 & $\mathrm{~N}$ & $0.63[0.27$, & 0.270 & $\mathrm{~N}$ & $0.34[0.03,3.36]$ & 0.360 & $\mathrm{~N}$ & $0.71[0.30$ & 0.440 & $\mathrm{~N}$ & $0.18[0.02$, & 0.150 & $\mathrm{~N}$ \\
\hline North Europe & 2 & $0.82[0.67$ & 0.070 & 0 & $0.68[0.51$, & 0.006 & 0 & $1.04[0.66,1.65]$ & 0.850 & 0 & $0.64[0.47$, & 0.003 & 0 & $0.88[0.54$ & 0.590 & 0 \\
\hline East Asian & 5 & $1.13[0.93$, & 0.220 & 26 & $1.17[0.88$, & 0.280 & 45 & $1.31[0.54,3.19]$ & 0.560 & 55 & $1.13[0.83$, & 0.430 & 55 & $1.20[0.72$, & 0.490 & 0 \\
\hline West Asian & 2 & $1.50[0.96$ & 0.070 & 56 & $1.61[0.64$, & 0.310 & 78 & $2.32[0.95,5.70]$ & 0.070 & 54 & $1.44[0.52$, & 0.490 & 81 & $2.48[1.28$, & 0.007 & 0 \\
\hline \multicolumn{17}{|l|}{ Sample Size } \\
\hline$\leq 300$ & 5 & $1.31[0.93$ & 0.130 & 60 & $1.36[0.87$, & 0.180 & 63 & $2.05[1.02,4.10]$ & 0.040 & 39 & $1.36[0.86$, & 0.190 & 59 & $1.58[0.71$, & 0.260 & 40 \\
\hline$>300$ & 7 & $0.99[0.87$ & 0.890 & 8 & $0.94[0.76$, & 0.570 & 40 & $1.09[0.75,1.57]$ & 0.660 & 20 & $0.90[0.72$, & 0.360 & 47 & $1.11[0.80$, & 0.550 & 0 \\
\hline \multicolumn{17}{|l|}{ Genotyping } \\
\hline PCR-RFLP & 2 & $1.49[0.91$, & 0.120 & 59 & $1.67[0.76$, & 0.200 & 75 & $1.84[0.93,3.62]$ & 0.080 & 0 & $1.72[0.89$, & 0.110 & 53 & $1.96[0.78$, & 0.150 & 38 \\
\hline PCR-SSCP & 5 & $1.15[0.88$ & 0.310 & 56 & $1.13[0.82$, & 0.440 & 52 & $1.37[0.64,2.95]$ & 0.420 & 60 & $1.10[0.80$, & 0.580 & 49 & $1.40[0.78$, & 0.260 & 32 \\
\hline PCR-TAQMAN & 2 & $0.82[0.67$, & 0.070 & 0 & $0.68[0.51$, & 0.006 & 0 & $1.04[0.66,1.65]$ & 0.850 & 0 & $0.64[0.47$, & 0.003 & 0 & $0.88[0.54$, & 0.590 & 0 \\
\hline PCR-SNaPShot & 1 & $1.17[0.80$ & 0.410 & $\mathrm{~N}$ & $1.24[0.70$, & 0.460 & $\mathrm{~N}$ & $1.33[0.51,3.45]$ & 0.560 & $\mathrm{~N}$ & $1.11[0.69$, & 0.680 & $\mathrm{~N}$ & $1.45[0.55$, & 0.450 & $\mathrm{~N}$ \\
\hline PCR-MassArray & 1 & $1.14[0.78$, & 0.490 & $\mathrm{~N}$ & $1.25[0.81$, & 0.310 & $\mathrm{~N}$ & $0.51[0.13,2.07]$ & 0.350 & $\mathrm{~N}$ & $1.32[0.84$ & 0.230 & $\mathrm{~N}$ & $0.66[0.16$, & 0.560 & $\mathrm{~N}$ \\
\hline PCR-GeXP & 1 & $1.03[0.55$, & 0.940 & $\mathrm{~N}$ & $0.81[0.41$, & 0.550 & $\mathrm{~N}$ & $26.22[1.54$ & 0.020 & $\mathrm{~N}$ & $0.66[0.33$, & 0.230 & $\mathrm{~N}$ & $4.56[0.26$, & 0.300 & $\mathrm{~N}$ \\
\hline \multicolumn{17}{|l|}{ Source of } \\
\hline PB & 2 & $0.82[0.67$, & 0.070 & 0 & $0.68[0.51$, & 0.006 & 0 & $1.04[0.66,1.65]$ & 0.850 & 0 & $0.64[0.47$, & 0.003 & 0 & $0.88[0.54$, & 0.590 & 0 \\
\hline HB & 10 & $1.19[1.01$, & 0.040 & 38 & $1.20[0.97$, & 0.090 & 44 & $1.49[0.91,2.43]$ & 0.110 & 47 & $1.16[0.93$, & 0.190 & 45 & $1.50[1.04$, & 0.030 & 73 \\
\hline
\end{tabular}

\section{Subgroup analysis}

To excavate the potential associations and underlying heterogeneity source from the pooled results, a subgroup analysis was performed and four subgroups (Region, Sample size, Genotyping method and source of controls) were stratified (Table 3).

In the subgroup analysis of Region, significant associations were found for these two polymorphisms. In the Middle Europe subgroup, the allelic genetic model (OR=1.63, 95\% KARGER 
Zhang et al.: MTHFR C677T and A1298C Polymorphisms and Fetal Congenital Heart Disease Risk

Table 3. Subgroup analysis of the associations of MTHFR polymorphisms with congenital heart disease risk. $\mathrm{OR}=$ odd ratio; $\mathrm{CI}=$ Confidence Interval; $\mathrm{HB}=$ Hospital Based; $\mathrm{PB}=$ Population Based; \# P value for HardyWeinberg equilibrium test in controls; * $\mathrm{P}$ value for meta-analysis. PCR-RFLP = polymerase chain reactionrestriction fragment length polymorphism. PCR-TAQMAN = polymerase chain reaction with Taqman probe; PCR-ABD = polymerase chain reaction using Assay by Design (ABD) kits from Applied Biosystems (Carlsbad, CA, USA): PCR-MassaArray Assay= Polymerase Chain Reaction with MassArray Assay. PCR-SSCP $=$ Polymerase Chain Reaction-Single Strand Conformation Polymorphism; PCR-SNaPShot = polymerse chain reaction with SNaPShot; PCR-GeXP = Polymerse Chain Reaction with GeXP. Significant results are marked in bold

\begin{tabular}{|c|c|c|c|c|c|c|c|c|c|c|c|c|c|c|c|c|c|}
\hline First author & Year & Country & \multicolumn{2}{|r|}{ Region } & \multicolumn{3}{|c|}{$\begin{array}{c}\text { Genotyping } \\
\text { method }\end{array}$} & $\begin{array}{l}\text { Controls } \\
\text { Source }\end{array}$ & case & control & $\mathrm{CC}$ & \multicolumn{2}{|l|}{ Case } & \multicolumn{3}{|c|}{ Control } & HWE \\
\hline \multicolumn{18}{|c|}{ MTHFR C677T Polymorphism } \\
\hline Junker [14] & 2001 & Germany & \multicolumn{3}{|c|}{ Middle Europe } & \multicolumn{2}{|c|}{ PCR-SSCP } & HB & 114 & 228 & 51 & 42 & 21 & 129 & 78 & 21 & 0.075 \\
\hline Yan [16] & 2003 & China & \multicolumn{2}{|r|}{ East Asian } & \multicolumn{3}{|c|}{ PCR-RFLP } & HB & 187 & 103 & 32 & 97 & 58 & 22 & 57 & 24 & 0.277 \\
\hline Li [18] & 2005 & China & & East Asian & & PCR-RF & & HB & 187 & 102 & 32 & 94 & 61 & 20 & 57 & 25 & 0.224 \\
\hline Lee [17] & 2005 & China & & East Asian & & PCR-SS & & HB & 213 & 195 & 110 & 89 & 14 & 114 & 68 & 13 & 0.513 \\
\hline Zhu [21] & 2006 & China & & East Asian & & PCR-RF & & PB & 56 & 103 & 7 & 22 & 27 & 22 & 57 & 24 & 0.277 \\
\hline van Driel [24] & 2008 & Netherlands & & orth Europe & & PCR-TAQI & MAN & PB & 229 & 251 & 99 & 103 & 27 & 119 & 107 & 25 & 0.895 \\
\hline Li [25] & 2009 & China & & East Asian & & PCR-RF & & HB & 144 & 168 & 26 & 52 & 66 & 49 & 84 & 35 & 0.928 \\
\hline $\mathrm{Xu}[27]$ & 2010 & China & & East Asian & & PCR-SS & & HB & 502 & 527 & 162 & 244 & 96 & 151 & 261 & 115 & 0.911 \\
\hline Kuehl [26] & 2010 & American & & rth America & & PCR-TAQI & MAN & PB & 55 & 290 & 12 & 33 & 10 & 134 & 124 & 32 & 0.682 \\
\hline Obermann-Borst [28] & 2011 & Netherlands & & prth Europe & & PCR-TAQI & MAN & PB & 139 & 183 & 64 & 66 & 9 & 92 & 76 & 15 & 0.900 \\
\hline Zhou [31] & 2012 & China & & East Asian & & PCR-SS & & HB & 136 & 277 & 23 & 60 & 53 & 88 & 126 & 63 & 0.168 \\
\hline $\mathrm{Li}[30]$ & 2012 & China & & East Asian & & PCR-RF & & HB & 144 & 168 & 26 & 52 & 66 & 49 & 84 & 35 & 0.928 \\
\hline Gong [29] & 2012 & China & & East Asian & & R-MassArr & ay Assay & HB & 244 & 136 & 45 & 123 & 76 & 43 & 72 & 21 & 0.309 \\
\hline Studv or Subgrou & & $\begin{array}{c}\text { CHD } \\
\text { Events } \\
\end{array}$ & Total & $\begin{array}{c}\text { Contrc } \\
\text { Events } \\
\end{array}$ & $\begin{array}{l}\text { ol } \\
\text { Total }\end{array}$ & Weight & $\begin{array}{r}\text { Odd } \\
\mathrm{M}-\mathrm{H}, \mathrm{Fi}\end{array}$ & $\begin{array}{l}\text { Ratio } \\
\text { ked, } 95 \% \mathrm{Cl}\end{array}$ & Year & & & $\begin{array}{r}O \\
M-H_{1}\end{array}$ & Ids F & $5 \% \mathrm{Cl}$ & & & \\
\hline Storti 2003 [15] & & 11 & 103 & 13 & 116 & $11.1 \%$ & 0.95 & {$[0.40,2.22]$} & 2003 & & & & & & & & \\
\hline Galdieri 2007 [22] & & 1 & 57 & 3 & 60 & $2.9 \%$ & 0.34 & {$[0.03,3.36]$} & 2007 & & & & & & & & \\
\hline van Driel 2008 [24 & & 27 & 229 & 25 & 254 & $21.3 \%$ & 1.22 & {$[0.69,2.18]$} & 2008 & & & & & & & & \\
\hline Xu 2010 [27] & & 18 & 502 & 16 & 518 & $15.5 \%$ & 1.17 & {$[0.59,2.31]$} & 2010 & & & & & & & & \\
\hline Obermann-Borst & 0011 [28] & 13 & 139 & 18 & 157 & $15.6 \%$ & 0.80 & {$[0.38,1.69]$} & 2011 & & & & & & & & \\
\hline Christensen 2013 & & 12 & 157 & 5 & 162 & $4.6 \%$ & 2.60 & {$[0.89,7.56]$} & 2013 & & & & & & & & \\
\hline Wang 2013 [34] & & 10 & 170 & 8 & 178 & $7.5 \%$ & 1.33 & {$[0.51,3.45]$} & 2013 & & & & & & & & \\
\hline Sahiner 2014 [38] & & 24 & 137 & 8 & 145 & $6.5 \%$ & 3.64 & {$[1.57,8.41]$} & 2014 & & & & & & & & \\
\hline Huang 2014 [37] & & 3 & 170 & 6 & 176 & $5.9 \%$ & 0.51 & {$[0.13,2.07]$} & 2014 & & & & & & & & \\
\hline Sayin 2015 [45] & & 13 & 69 & 11 & 80 & $8.4 \%$ & 1.46 & {$[0.61,3.50]$} & 2015 & & & & & & & & \\
\hline Li 2015 [41] & & 0 & 150 & 0 & 150 & & & t estimable & 2015 & & & & & & & & \\
\hline Feng 2016 [42] & & 12 & 257 & 0 & 257 & $0.5 \%$ & $26.22[1$ & $54,445.28]$ & 2016 & & & & & & & & \\
\hline Total $(95 \% \mathrm{Cl})$ & & & 2140 & & 2253 & $100.0 \%$ & 1.42 & {$[1.10,1.84]$} & & & & & & & & & \\
\hline Total events & & 144 & & 113 & & & & & & & & & & & & & \\
\hline $\begin{array}{l}\text { Heterogeneity: } \mathrm{Ch} \\
\text { Test for overall eff }\end{array}$ & $\begin{array}{l}z^{2}=17.42 \\
\text { ect: } Z=2\end{array}$ & $\begin{array}{l}2, \mathrm{df}=10(\mathrm{P}= \\
2.67(\mathrm{P}=0.00\end{array}$ & $\begin{array}{l}=0.07) ; \\
\text { g) }\end{array}$ & 7); $\left.\right|^{2}=43 \%$ & & & & & & 0.1 & 0.2 & $\begin{array}{r}0.5 \\
\text { Proteci }\end{array}$ & ${ }^{1}$ & $\begin{array}{r}1 \\
2 \\
\text { sky }\end{array}$ & 5 & 10 & \\
\hline
\end{tabular}

Fig. 3. Pooled analysis of A1298C polymorphism and CHD risk in children population. 


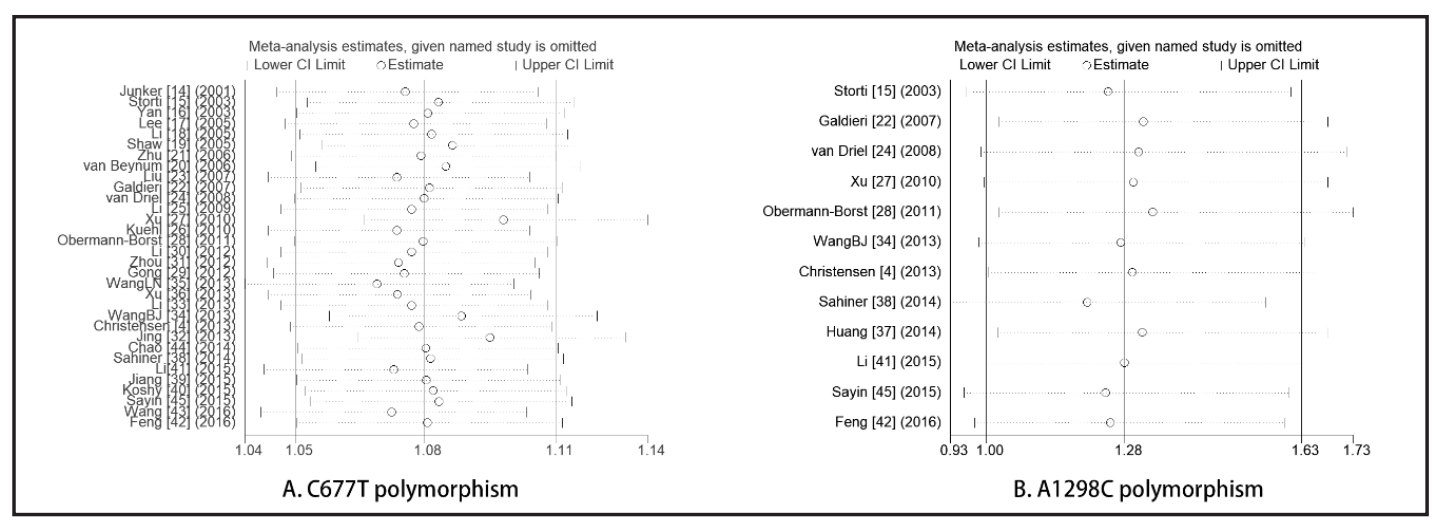

Fig. 4. Sensitivity analysis of C677T and A1298C polymorphism and CHD risk.

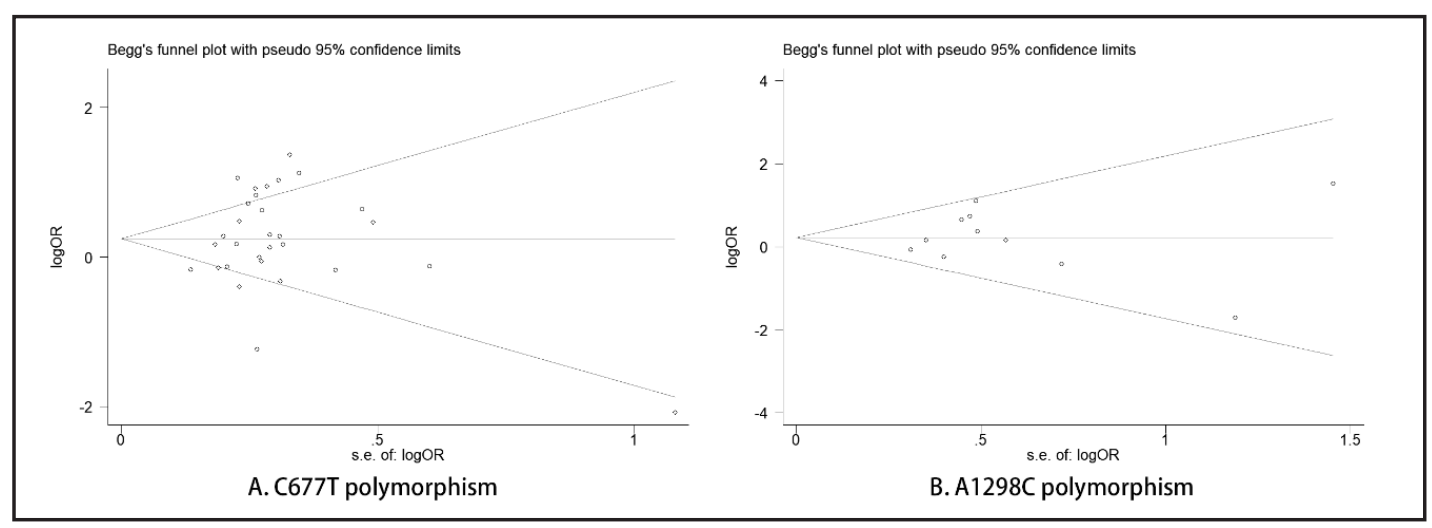

Fig. 5. Publication bias of C677T and A1298C polymorphism and CHD risk.

$\mathrm{CI}=1.16-2.30, \mathrm{P}=0.005)$, dominant genetic model $(\mathrm{TT}+\mathrm{TC}$ versus $\mathrm{CC}(\mathrm{OR}=1.61,95 \% \mathrm{CI}=1.02$ $2.53, \mathrm{P}=0.04)$ and homozygote genetic model $(\mathrm{OR}=2.53,95 \% \mathrm{CI}=1.27-5.02, \mathrm{P}=0.008)$ of the C677T polymorphism were associated with CHD risk. All five-genetic model of the C677T polymorphism in the East Asian were observed to be associated with CHD risk but also with high heterogeneity. For A1298C polymorphism, the dominant genetic model $(\mathrm{OR}=0.68$, $95 \% \mathrm{CI}=0.51-0.90, \mathrm{P}=0.006)$ and heterozygote genetic model $(\mathrm{OR}=0.64,95 \% \mathrm{CI}=0.47-0.86$, $\mathrm{P}=0.003)$ in the North Europe subgroup and the homozygote genetic model (OR=2.48, 95\% $\mathrm{CI}=1.28-4.81, \mathrm{P}=0.007$ ) in the West Asian subgroup were related to CHD risk.

In the subgroup analysis of Sample size, for the C677T polymorphism, wide significant associations with reduced heterogeneity were observed in the no more than 300 subgroup as follows: the allelic genetic model $(\mathrm{OR}=1.32,95 \% \mathrm{CI}=1.08-1.80, \mathrm{P}=0.006)$; the dominant genetic model $(\mathrm{OR}=1.35,95 \% \mathrm{CI}=1.01-1.80, \mathrm{P}=0.04)$; the recessive genetic model $(\mathrm{OR}=2.41$, 95\% $\mathrm{CI}=1.81-3.21, \mathrm{P}=0.000)$; and the homozygote genetic model $(\mathrm{OR}=1.91,95 \% \mathrm{CI}=1.36$ 2.67, $\mathrm{P}=0.0002)$ ). As for more than 300 subgroup, the allelic genetic model (OR=1.34, 95\% $\mathrm{CI}=1.10-1.64, \mathrm{P}=0.004)$, dominant genetic model $(\mathrm{OR}=1.36,95 \% \mathrm{CI}=1.06-1.76, \mathrm{P}=0.02)$ and homozygote genetic model $(\mathrm{OR}=1.73,95 \% \mathrm{CI}=1.17-2.56, \mathrm{P}=0.006)$ were associated with CHD risk. However, for the A1298C polymorphism, a significant association with reduced heterogeneity was only detected in the recessive genetic model $(\mathrm{OR}=2.05,95 \% \mathrm{CI}=1.02$ $4.10, \mathrm{P}=0.04$ ) in the no more than 300 subgroup.

As for the subgroup analysis stratified by the genotyping method, extensive significant associations were found in the C677T polymorphism by PCR-RFLP for the allelic genetic model $(\mathrm{OR}=1.36,95 \% \mathrm{CI}=1.03-1.80, \mathrm{P}=0.03)$, recessive genetic model $(\mathrm{OR}=2.26,95 \%$ $\mathrm{CI}=1.51-3.39, \mathrm{P}=0.0001)$, homozygote genetic model $(\mathrm{OR}=1.95,95 \% \mathrm{CI}=1.16-3.29$, $\mathrm{P}=0.0001)$, by PCR-SSCP for the allelic genetic model ( $\mathrm{OR}=1.34,95 \% \mathrm{CI}=1.06-1.71, \mathrm{P}=0.02)$, recessive genetic model $(\mathrm{OR}=1.48,95 \% \mathrm{CI}=1.07-2.06, \mathrm{P}=0.02)$, homozygote genetic model 


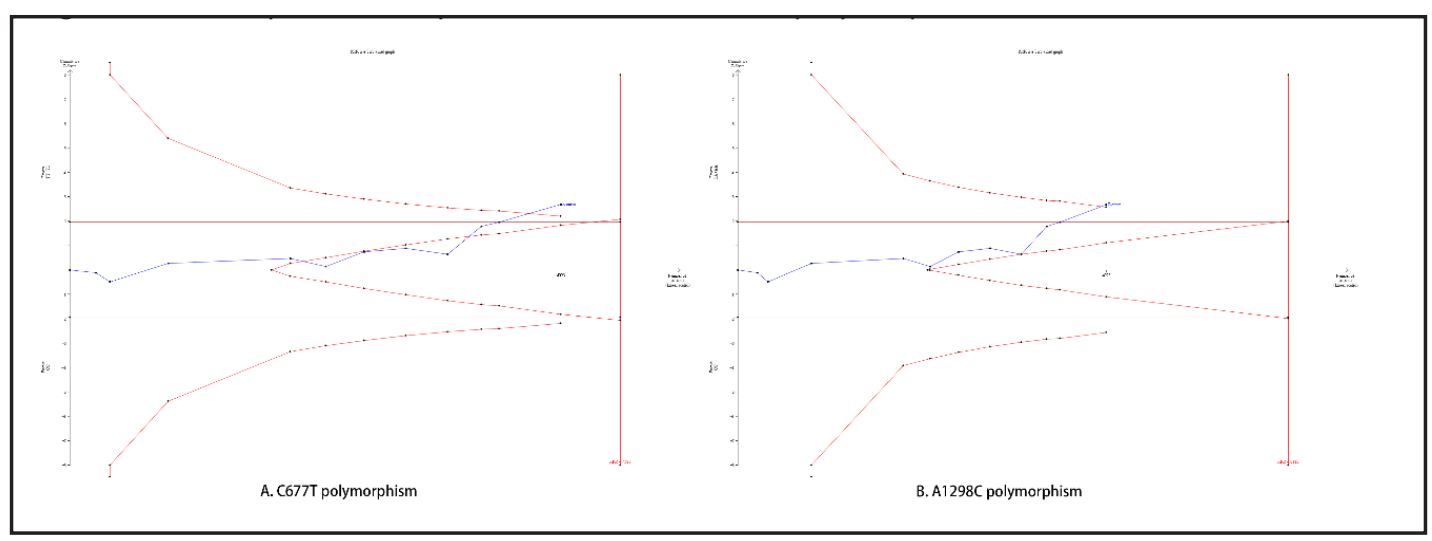

Fig. 6. Trial sequential analysis of C677T and A1298C polymorphism and CHD risk.

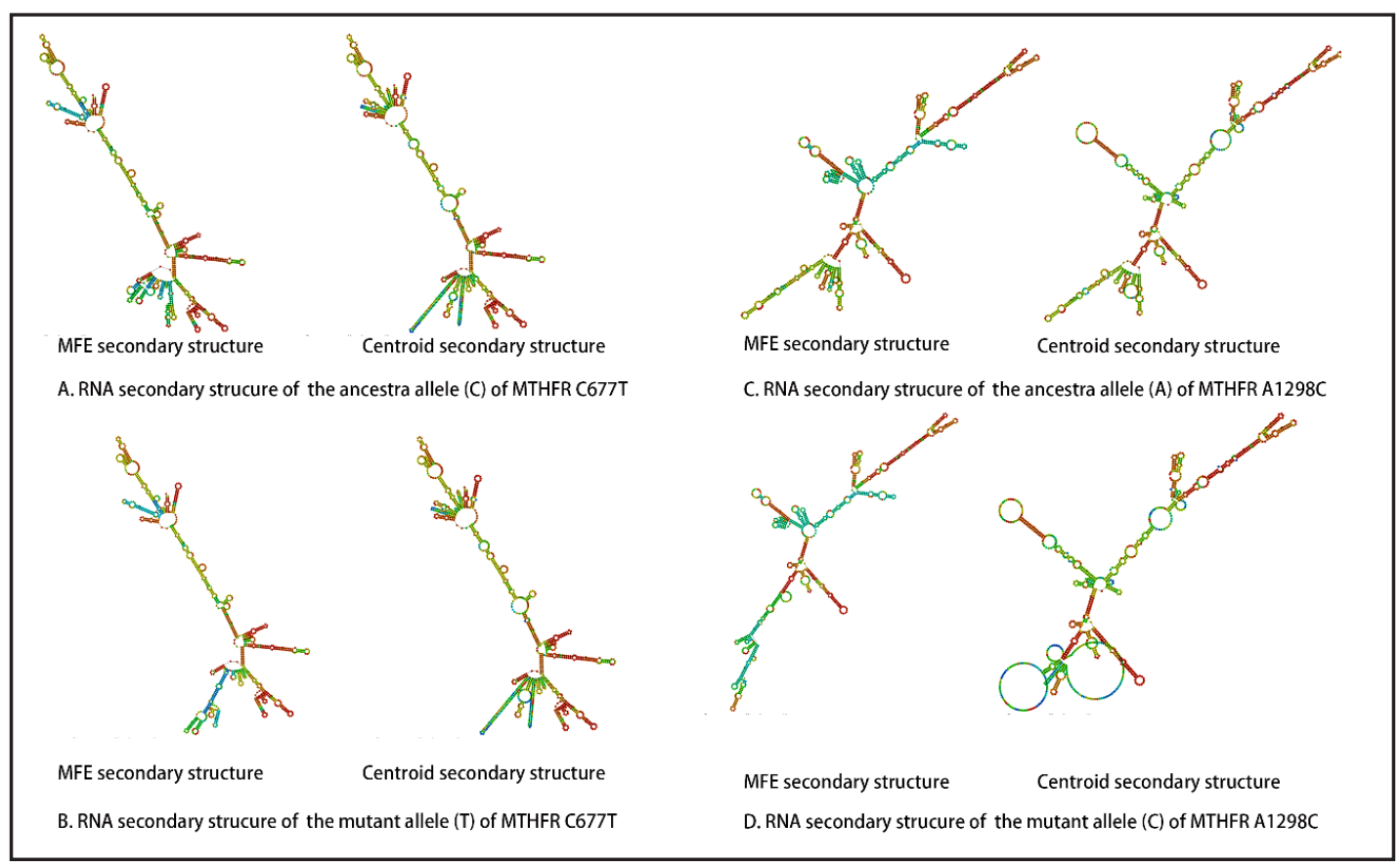

Fig. 7. RNAfold Webserver analysis of C677T and A1298C polymorphism and CHD risk.

(OR=1.77, 95\% CI=1.13-2.79, $\mathrm{P}=0.01)$, by the PCR-MassArray Assay for the allelic genetic model $(\mathrm{OR}=2.05,95 \% \mathrm{CI}=1.02-4.10, \mathrm{P}=0.04)$, dominant genetic model $(\mathrm{OR}=2.04,95 \%$ $\mathrm{CI}=1.26-3.32, \mathrm{P}=0.004)$, recessive genetic model $(\mathrm{OR}=5.26,95 \% \mathrm{CI}=3.12-8.86, \mathrm{P}=0.000)$, and homozygote genetic model $(\mathrm{OR}=3.46,95 \% \mathrm{CI}=1.83-6.55, \mathrm{P}=0.0001)$, by PCR-SNaPShot for the dominant genetic model $(\mathrm{OR}=2.86,95 \% \mathrm{CI}=1.83-4.48, \mathrm{P}=0.000)$ and heterozygote genetic model (OR=1.95, 95\% CI=1.20-3.15, $\mathrm{P}=0.04)$, by PCR-GeXP for the dominant genetic model (OR=3.91, 95\% CI=2.06-7.44, $\mathrm{P}=0.0001)$, recessive genetic model $(\mathrm{OR}=11.46,95 \%$ $\mathrm{CI}=6.91-19.03, \mathrm{P}=0.000)$ ). However, for A1298C polymorphism, significant associations were only observed by PCR-TAQMAN (dominant genetic model: OR=0.68, 95\% CI=0.51-0.90, $\mathrm{P}=0.006$; heterozygote genetic model: $\mathrm{OR}=0.64,95 \% \mathrm{CI}=0.47-0.86, \mathrm{P}=0.003$ ) and PCR-GeXP (recessive genetic model: $\mathrm{OR}=26.22,95 \% \mathrm{CI}=1.54-445.28, \mathrm{P}=0.02$ ).

In the subgroup analysis of the source of controls, for the C677T polymorphism, significant associations were only observed in the hospital based subgroup (Allelic genetic model: $\mathrm{OR}=1.34,95 \% \mathrm{CI}=1.12-1.59, \mathrm{P}=0.001$; dominant genetic model: $\mathrm{OR}=1.37,95 \%$ $\mathrm{CI}=1.08-1.73, \mathrm{P}=0.009$; recessive genetic model: $\mathrm{OR}=2.03,95 \% \mathrm{CI}=1.47-2.80, \mathrm{P}=0.0001$;

\section{KARGER}


homozygote genetic model: $\mathrm{OR}=1.81,95 \% \mathrm{CI}=1.29-2.53, \mathrm{P}=0.0006)$. For the $\mathrm{A} 1298 \mathrm{C}$ polymorphism, the heterozygote genetic model $(\mathrm{OR}=0.64,95 \% \mathrm{CI}=0.47-0.86, \mathrm{P}=0.003)$ in the population based subgroup and the allelic genetic model $(\mathrm{OR}=1.19,95 \% \mathrm{CI}=1.01-1.41$, $\mathrm{P}=0.04)$ and homozygote genetic model $(\mathrm{OR}=1.50,95 \% \mathrm{CI}=1.04-2.16, \mathrm{P}=0.03)$ in the hospital based subgroup were associated with CHD risk.

\section{Sensitivity analyses}

The sensitivity analysis was conducted by sequentially omitting 1 individual study every time to weigh the influence of each study on the overall meta-analysis. No significant change in the heterogeneity was observed for these two polymorphisms (Fig. 4).

\section{Publication bias}

No publication bias was detected among the studies regarding the association between the C677T and A1298C polymorphism and congenital heart defect risk (Fig. 5).

\section{Trial sequential analysis}

According to the settings mentioned in the method section, we calculated the required information size for the MTHFR C677T and A1298C polymorphisms (Fig. 6). The number of patients included in the meta-analysis exceeded the required information size for the two polymorphisms, which indicated our positive results were confirmed by TSA.

\section{RNA secondary structure analysis}

We conducted an RNA secondary structure analysis of the MTHFR C677T and A1298C polymorphisms with the RNAfold Webserver. Fig. 7 shows the significant changes in the RNA structure under both the minimum free energy and the centroid secondary structure, which indicated the two variants might affect the stability of the RNA secondary structure.

\section{Discussion}

The methylenetetrahydrofolate reductase (MTHFR) is the crucial enzyme concatenating the folate pathway and homocysteine metabolism [46]. Low folate and high homocysteine are a closely related with the occurrence of congenital heart disease $[5,47]$, which indicates that single nucleotide polymorphisms (SNPs) in the MTHFR gene may be genetic risk factors for these disorders. The MTHFR C677T and A1298C SNPs are common and functional, with enough data for us to perform a subgroup analysis and a trial sequential analysis. Moreover, the mutant $677 \mathrm{~T}$ and $1298 \mathrm{C}$ alleles are related to the decreased activity of the MTHFR enzyme [48]. Therefore, we chose these two polymorphisms to investigate their associations with CHD risk and significant increased risks were widely observed in both the overall and subgroup analyses.

An increased risk of CHD was detected in the MTHFR C677T polymorphism from the overall analysis. The putative risk allele-677T had a 32\% increased risk of CHD risk against the C-allele. A 35\% increase in CHD risk in the TT+TC genotypes was also detected. The TC and TT genotypes increased CHD risk by $20 \%$ and $75 \%$ compared to the CC genotype respectively. In addition, a $69 \%$ increased risk was also found in the TT genotypes compared to TC+CC genotypes. Moreover, the increased risk of the T allele, TT, TC and TT+TC genotypes was widely observed in the subgroup analysis stratified by region, sample size, genotyping method and source of controls. Furthermore, the TSA test confirmed our positive results. The extensive increased risk of the C677T polymorphism in CHD implied this polymorphism was a strong genetic risk factor for fetal heart defects.

As for the MTHFR A1298C polymorphism, the increased risk of the CC genotype was widely detected both from the pooled analysis and the subgroup analysis (West Asian subgroup, no more than 300 subgroup, PCR-GeXP subgroup and hospital-based subgroup), and the positive result was verified by TSA. Interesting results sprouted in the North Europe 


\section{Cellular Physiology Cell Physiol Biochem 2018;45:2483-2496

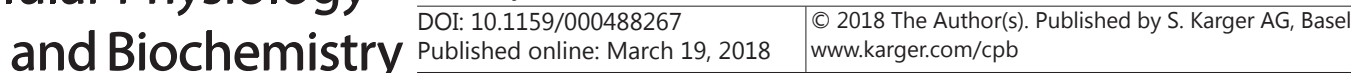

Zhang et al.: MTHFR C677T and A1298C Polymorphisms and Fetal Congenital Heart

Disease Risk

and PCR-TAQMAN subgroup; a protective role for the CA+AA and CA genotypes was observed. Several studies also report the protective role of $1298 \mathrm{C}$ allele, and Hobbs et al. suggested three possible explanations for the phenomenon, including: (i) an unknown functional polymorphism in linkage disequilibrium with A1298C, (ii) error-free DNA synthesis with abundant purines and pyrimidines caused by the lower activity of the MTHFR enzyme, and (iii) the selective survival of the 1298A allele [49-51]. In summary, the CC genotype of the MTHFR A1298C polymorphism had an increased risk of CHD, but the protective role of 1298C allele should be interpreted with caution.

Previous meta-analysises have also drawn a conclusion showing a significant association between the MTHFR polymorphism and CHD [52-57]. The differences between our analysis and the former analyses was the sample size and the exclusion of studies with departure from the Hardy-Weinberg equilibrium. We added new references to expand the sample size for better reaching the significant results. Moreover, studies with departure from the Hardy-Weinberg equilibrium were excluded for homogeneity in the control groups, which would make our results more reliable and stable. Additionally, a trial sequential analysis was conducted to strengthen our positive results. Furthermore, the MTHFR C677T polymorphism was highly associated with homocysteine concentrations in the large scale, methodologically independent genome-wide association study [58]. However, no genome-wide association study about the A1298C polymorphism is reported so far.

Reduced MTHFR enzyme activity decreases the synthesis of 5-methyl-tetrahydrofolate (the substrate vital for DNA synthase), interrupts the homocysteine remethylation to methionine (a decreased pool of which may affect DNA methylation), and induces hyperhomocysteinemia [45]. Hyperhomocysteinemia initiates apoptosis in neural crest cells and has embryotoxic effects in heart cells in animal models [59, 60]. Although the MTHFR C677T and A1298C polymorphisms both diminish MTHFR enzyme activity, they act in different ways. The 677T variant causes a thermolabile form of the enzyme and is associated with elevated homocysteine levels, but for 1298C, it reduced the enzyme activity by conformational changes of the enzyme that occur after S-adenosyl-methionine regulatory domain binding $[61,62]$. Our RNA secondary structure analysis showed that the mutant $677 \mathrm{~T}$ and $1298 \mathrm{C}$ alleles changed the space conformation of the RNA secondary structure of the MTHFR gene and influenced the stability of this gene, which may be an explanation for the termolabile form of enzyme caused by the $677 \mathrm{~T}$ allele and the conformational changes of the enzyme induced by the $1298 \mathrm{C}$ allele.

Several limitations were existed in this meta-analysis. First, only English and Chinese databases were searched in our study; a selection of the literature without other language may bias the results. Second, the individual patient heterogeneity and confounding factors might have distorted the analysis. Third, the sample size of the included studies was relatively small in some subgroups, especially for the A1298C polymorphism, which implied that part of our results should be explained with caution. In addition, the potential influence of maternal environment factors on these two polymorphisms is worthy of consideration.

\section{Conclusion}

The MTHFR C677T polymorphism was associated with a significant increase in congenital heart defect risk in the fetal population based on our analysis. Moreover, the increased risk in the CC genotype of the MTHFR A1298C polymorphism was observed, but the protective role of the $1298 \mathrm{C}$ allele needs further study.

\section{Disclosure Statement}

No conflict of interests exists. 


\section{Cellular Physiology Cell Physiol Biochem 2018;45:2483-2496 \begin{tabular}{l|l} 
and Biochemistry Published online: March 19, 2018 & $\begin{array}{l}\text { (c) } 2018 \text { The Author(s). Published by S. Karger AG, Basel } \\
\text { www.karger.com/cpb }\end{array}$
\end{tabular}}

Zhang et al.: MTHFR C677T and A1298C Polymorphisms and Fetal Congenital Heart Disease Risk

\section{References}

1 Mitchell SC, Korones SB, Berendes HW: Congenital heart disease in 56, 109 births. Incidence and natural history. Circulation 1971;43:323-332.

-2 van der Bom T, Zomer AC, Zwinderman AH, Meijboom FJ, Bouma BJ, Mulder BJ: The changing epidemiology of congenital heart disease. Nat Rev Cardiol 2011;8:50-60.

- 3 Shi H, Yang S, Liu Y, Huang P, Lin N, Sun X, Yu R, Zhang Y, Qin Y, Wang L: Study on Environmental Causes and SNPs of MTHFR, MS and CBS Genes Related to Congenital Heart Disease. PloS One 2015;10:e0128646.

4 Christensen KE, Zada YF, Rohlicek CV, Andelfinger GU, Michaud JL, Bigras JL, Richter A, Dube MP, Rozen R: Risk of congenital heart defects is influenced by genetic variation in folate metabolism. Cardiol Young 2013;23:89-98. Hall J, Solehdin F: Folic acid for the prevention of congenital anomalies. Eur J Pediatr 1998;157:445-450. Biselli PM, Guerzoni AR, de Godoy MF, Eberlin MN, Haddad R, Carvalho VM, Vannucchi H, Pavarino-Bertelli EC, Goloni-Bertollo EM: Genetic polymorphisms involved in folate metabolism and concentrations of methylmalonic acid and folate on plasma homocysteine and risk of coronary artery disease. J Thromb Thrombolysis 2010;29:32-40.

7 Hernandez-Diaz S, Werler MM, Walker AM, Mitchell AA: Folic acid antagonists during pregnancy and the risk of birth defects. N Engl J Med 2000;343:1608-1614.

-8 Wenstrom KD, Johanning GL, Johnston KE, DuBard M: Association of the C677T methylenetetrahydrofolate reductase mutation and elevated homocysteine levels with congenital cardiac malformations. Am J Obstet Gynecol 2001;184:806-812; discussion 812-807.

-9 Moher D, Liberati A, Tetzlaff J, Altman DG, Group P: Preferred reporting items for systematic reviews and meta-analyses: the PRISMA statement. Int J Surg 2010;8:336-341.

10 Sun Y, Chen J, Li H, Jiang J, Chen S: Steroid Injection and Nonsteroidal Anti-inflammatory Agents for Shoulder Pain: A PRISMA Systematic Review and Meta-Analysis of Randomized Controlled Trials. Medicine (Baltimore) 2015;94:e2216.

11 Xin XY, Ding JQ Chen SD: Apolipoprotein E promoter polymorphisms and risk of Alzheimer's disease: evidence from meta-analysis. J Alzheimers Dis 2010;19:1283-1294.

12 Gruber AR, Lorenz R, Bernhart SH, Neubock R, Hofacker IL: The Vienna RNA websuite. Nucleic Acids Res 2008;36:W70-74.

13 Zuker M, Stiegler P: Optimal computer folding of large RNA sequences using thermodynamics and auxiliary information. Nucleic Acids Res 1981;9:133-148.

14 Junker R, Kotthoff S, Vielhaber H, Halimeh S, Kosch A, Koch HG, Kassenbohmer R, Heineking B, Nowak-Gottl $\mathrm{U}$ : Infant methylenetetrahydrofolate reductase 677TT genotype is a risk factor for congenital heart disease. Cardiovasc Res 2001;51:251-254.

15 Storti S, Vittorini S, Iascone MR, Sacchelli M, Collavoli A, Ripoli A, Cocchi G, Biagini A, Clerico A: Association between 5, 10-methylenetetrahydrofolate reductase C677T and A1298C polymorphisms and conotruncal heart defects. Clin Chem Lab Med 2003;41:276-280.

16 Yan L, Li Y: Relationship of MTHFR gene C677T polymorphism with congenital heart disease. Beijing Da Xue Xue Bao Yi Xue Ban 2003;35:448-449.

-17 Lee CN, Su YN, Cheng WF, Lin MT, Wang JK, Wu MH, Hsieh FJ: Association of the C677T methylenetetrahydrofolate reductase mutation with congenital heart diseases. Acta Obstet Gynecol Scand 2005;84:1134-1140.

18 Li Y, Cheng J, Zhu WL, Dao JJ, Yan LY, Li MY, Li SQ: [Study of serum Hcy and polymorphisms of Hcy metabolic enzymes in 192 families affected by congenital heart disease]. Beijing Da Xue Xue Bao Yi Xue Ban 2005;37:75-80.

19 Shaw GM, Iovannisci DM, Yang W, Finnell RH, Carmichael SL, Cheng S, Lammer EJ: Risks of human conotruncal heart defects associated with 32 single nucleotide polymorphisms of selected cardiovascular disease-related genes. Am J Med Genet A 2005;138:21-26.

20 van Beynum IM, Kapusta L, den Heijer M, Vermeulen SH, Kouwenberg M, Daniels O, Blom HJ: Maternal MTHFR $677 \mathrm{C}>\mathrm{T}$ is a risk factor for congenital heart defects: effect modification by periconceptional folate supplementation. Eur Heart J 2006;27:981-987.

21 Zhu WL, Li Y, Yan L, Dao J, Li S: Maternal and offspring MTHFR gene C677T polymorphism as predictors of congenital atrial septal defect and patent ductus arteriosus. Mol Hum Reprod 2006;12:51-54. 


\section{Cellular Physiology Cell Physiol Biochem 2018;45:2483-2496

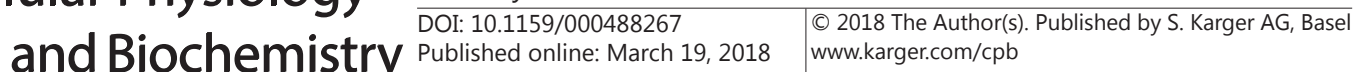

Zhang et al.: MTHFR C677T and A1298C Polymorphisms and Fetal Congenital Heart Disease Risk

-22 Galdieri LC, Arrieta SR, Silva CM, Pedra CA, D’Almeida V: Homocysteine concentrations and molecular analysis in patients with congenital heart defects. Arch Med Res 2007;38:212-218.

23 Liu YS, Yin XG, Wang JF, Yu LH, Liu HP, Meng FC, Liu DM: Relationship between genetic polymorphism of homocysteine metabolism enzyme and congenital hear t disease. Chin J Cardiovasc Rev 2007;5:210-213.

-24 van Driel LM, Verkleij-Hagoort AC, de Jonge R, Uitterlinden AG, Steegers EA, van Duijn CM, SteegersTheunissen RP: Two MTHFR polymorphisms, maternal B-vitamin intake, and CHDs. Birth Defects Res A Clin Mol Teratol 2008;82:474-481.

25 Li D, Jing XA, Hou HF, Fan H: A case-control study on the correlation between congenital heart disease and MTHFR gene as well as nutrition factors. Chin Prev Med 2009;10:990-993.

-26 Kuehl K, Loffredo C, Lammer EJ, Iovannisci DM, Shaw GM: Association of congenital cardiovascular malformations with 33 single nucleotide polymorphisms of selected cardiovascular disease-related genes. Birth Defects Res A Clin Mol Teratol 2010;88:101-110.

27 Xu J, Xu X, Xue L, Liu X, Gu H, Cao H, Qiu W, Hu Z, Shen H, Chen Y: MTHFR c.1793G>A polymorphism is associated with congenital cardiac disease in a Chinese population. Cardiol Young 2010;20:318-326.

28 Obermann-Borst SA, van Driel LM, Helbing WA, de Jonge R, Wildhagen MF, Steegers EA, SteegersTheunissen RP: Congenital heart defects and biomarkers of methylation in children: a case-control study. Eur J Clin Invest 2011;41:143-150.

29 Gong D, Gu H, Zhang Y, Gong J, Nie Y, Wang J, Zhang H, Liu R, Hu S, Zhang H: Methylenetetrahydrofolate reductase $\mathrm{C} 677 \mathrm{~T}$ and reduced folate carrier $80 \mathrm{G}>\mathrm{A}$ polymorphisms are associated with an increased risk of conotruncal heart defects. Clin Chem Lab Med 2012;50:1455-1461.

30 Li D, Ji L, Wang CL, Yuan CH: Studies on correlations between congenital heart disease and MTHFR C677T polymorhosm or unexpected stressful life events during pregnancy. Chin Prev Med 2012:428-431.

31 Zhou SY, Zhou JP, Wang LN, Xu N, Chang MX, Wang YL, Wang FY, Li CM: Study on the association between MTHFR gene polymorphism and tetralogy of fallot. Shandong Med 2012;52:1-3.

32 Jing XA, Wang HY, Li D, Ye WJ, Tan L: Associations of MTHFR gene polymorphism and environmental factors with congenital heart disease. Chin J Public Health 2013;29:347-349.

33 Li D, Ji L, Liu YZ, Yu KK, Wang CL, Yuan CH: Correlationship between congenital heart disease and MTHFR gene as well as illness duing pregnancy: a case-control study. Chin Prev Med 2013;14:586-589.

-34 Wang B, Liu M, Yan W, Mao J, Jiang D, Li H, Chen Y: Association of SNPs in genes involved in folate metabolism with the risk of congenital heart disease. J Matern Fetal Neonatal Med 2013;26:1768-1777.

35 Wang LN: Relationship between 5, 10-methylenetetrahydrofolate gene polymorphism and congenital heart disease in nuclear family. Chin J Appl Clin Pediatr Cardiol 2013;28:4.

36 Xu R, Huo Q, Zhang L, Ma L, Zhou Y: The association study on MTHFR gene polymorphism C677T and simple congenital heart disease in Uyghur and Han populations in Xinjiang. J Xinjiang Med Univ 2013;36:748-751+755.

-37 Huang J, Mei J, Jiang L, Jiang Z, Liu H, Ding F: MTHFR rs1801133 C>T polymorphism is associated with an increased risk of tetralogy of Fallot. Biomed Rep 2014;2:172-176.

-38 Sahiner UM, Alanay Y, Alehan D, Tuncbilek E, Alikasifoglu M: Methylene tetrahydrofolate reductase polymorphisms and homocysteine level in heart defects. Pediatr Int 2014;56:167-172.

-39 Jiang Y, Mei J, Zhang W, Qian X, Zhang S, Liu C, Yang H: [Correlation between offspring congenital heart disease and MTHFR 677C/T polymorphism and general status of pregnant women]. Zhonghua Liu Xing Bing Xue Za Zhi 2015;36:1072-1076.

40 Koshy T, Venkatesan V, Perumal V, Hegde S, Paul SF: The A1298C Methylenetetrahydrofolate Reductase Gene Variant as a Susceptibility Gene for Non-Syndromic Conotruncal Heart Defects in an Indian Population. Pediatr Cardiol 2015;36:1470-1475.

41 Li D, Yu K, Ma Y, Liu Y, Ji L: [Correlationship between congenital heart disease and polymorphism of MTHFR gene]. Wei Sheng Yan Jiu 2015;44:933-938.

42 Feng ZS, Zhao MC, Wang L, Li GX, Tao SG, Wen LL, Wang K, Ma XJ: The investigation of correlation between MTHF R gene polymorphism and congenital heart disease by means of GeXP multiplex analysis technique. J Hebei Med 2016;38:1143-1146.

43 Wang Y, Zhang H, Yue S, Zhang K, Wang H, Dong R, Yang X, Liu Y, Ma Y: Evaluation of High Resolution Melting for MTHFR C677T Genotyping in Congenital Heart Disease. PloS One 2016;11:e0151140.

44 Chao CS, Wei J, Huang HW, Yang SC: Correlation between methyltetrahydrofolate reductase (MTHFR) polymorphisms and isolated patent ductus arteriosus in Taiwan. Heart Lung Circ 2014;23:655-660. 


\section{Cellular Physiology Cell Physiol Biochem 2018;45:2483-2496 \begin{tabular}{l|l} 
and Biochemistry Published online: March 19, 2018 & $\begin{array}{l}\text { C) } 2018 \text { The Author(s). Published by S. Karger AG, Basel } \\
\text { www.karger.com/cpb }\end{array}$ \\
\hline
\end{tabular} \\ Zhang et al.: MTHFR C677T and A1298C Polymorphisms and Fetal Congenital Heart}

Disease Risk

45 Sayin Kocakap BD, Sanli C, Cabuk F, Koc M, Kutsal A: Association of MTHFR A1298C polymorphism with conotruncal heart disease. Cardiol Young 2015;25:1326-1331.

46 Brouns R, Ursem N, Lindemans J, Hop W, Pluijm S, Steegers E, Steegers-Theunissen R: Polymorphisms in genes related to folate and cobalamin metabolism and the associations with complex birth defects. Prenat Diagn 2008;28:485-493.

47 Leclerc D, Rozen R: [Molecular genetics of MTHFR: polymorphisms are not all benign]. Med Sci (Paris) 2007;23:297-302.

-48 Weisberg I, Tran P, Christensen B, Sibani S, Rozen R: A second genetic polymorphism in methylenetetrahydrofolate reductase (MTHFR) associated with decreased enzyme activity. Mol Genet Metab 1998;64:169-172.

49 Hobbs CA, James SJ, Parsian A, Krakowiak PA, Jernigan S, Greenhaw JJ, Lu Y, Cleves MA: Congenital heart defects and genetic variants in the methylenetetrahydroflate reductase gene. J Med Genet 2006;43:162166.

50 Goldmuntz E, Woyciechowski S, Renstrom D, Lupo PJ, Mitchell LE: Variants of folate metabolism genes and the risk of conotruncal cardiac defects. Circ Cardiovasc Genet 2008;1:126-132.

51 van Driel LM, Smedts HP, Helbing WA, Isaacs A, Lindemans J, Uitterlinden AG, van Duijn CM, de Vries JH, Steegers EA, Steegers-Theunissen RP: Eight-fold increased risk for congenital heart defects in children carrying the nicotinamide $\mathrm{N}$-methyltransferase polymorphism and exposed to medicines and low nicotinamide. Eur Heart J 2008;29:1424-1431.

52 Xuan C, Li H, Zhao JX, Wang HW, Wang Y, Ning CP, Liu Z, Zhang BB, He GW, Lun LM: Association between MTHFR polymorphisms and congenital heart disease: a meta-analysis based on 9, 329 cases and 15, 076 controls. Sci Rep 2014;4:7311.

53 Wang W, Wang Y, Gong F, Zhu W, Fu S: MTHFR C677T polymorphism and risk of congenital heart defects: evidence from 29 case-control and TDT studies. PloS One 2013;8:e58041.

-54 Wang W, Hou Z, Wang C, Wei C, Li Y, Jiang L: Association between 5, 10-methylenetetrahydrofolate reductase (MTHFR) polymorphisms and congenital heart disease: A meta-analysis. Meta gene 2013;1:109125.

55 Mamasoula C, Prentice RR, Pierscionek T, Pangilinan F, Mills JL, Druschel C, Pass K, Russell MW, Hall D, Topf A, Brown DL, Zelenika D, Bentham J, Cosgrove C, Bhattacharya S, Riveron JG, Setchfield K, Brook JD, Bu'Lock FA, Thornborough C, Rahman TJ, Doza JP, Tan HL, O’Sullivan J, Stuart AG, Blue G, Winlaw D, Postma AV, Mulder BJ, Zwinderman AH, van Engelen K, Moorman AF, Rauch A, Gewillig M, Breckpot J, Devriendt K, Lathrop GM, Farrall M, Goodship JA, Cordell HJ, Brody LC, Keavney BD: Association between C677T polymorphism of methylene tetrahydrofolate reductase and congenital heart disease: meta-analysis of 7697 cases and 13, 125 controls. Circ Cardiovasc Genet 2013;6:347-353.

56 Li Z, Jun Y, Zhong-Bao R, Jie L, Jian-Ming L: Association between MTHFR C677T polymorphism and congenital heart disease. A family-based meta-analysis. Herz 2015;40:S160-167.

57 Chen KH, Chen LL, Li WG, Fang Y, Huang GY: Maternal MTHFR C677T polymorphism and congenital heart defect risk in the Chinese Han population: a meta-analysis. Genet Mol Res 2013;12:6212-6219.

58 Tanaka T, Scheet P, Giusti B, Bandinelli S, Piras MG, Usala G, Lai S, Mulas A, Corsi AM, Vestrini A, Sofi F, Gori AM, Abbate R, Guralnik J, Singleton A, Abecasis GR, Schlessinger D, Uda M, Ferrucci L: Genome-wide association study of vitamin B6, vitamin B12, folate, and homocysteine blood concentrations. Am J Hum Genet 2009;84:477-482.

59 Miller PN, Pratten MK, Beck F: Growth of 9.5-day rat embryos in folic-acid-deficient serum. Teratology 1989;39:375-385.

60 Burgoon JM, Selhub J, Nadeau M, Sadler TW: Investigation of the effects of folate deficiency on embryonic development through the establishment of a folate deficient mouse model. Teratology 2002;65:219-227.

61 Robien K, Ulrich CM: 5, 10-Methylenetetrahydrofolate reductase polymorphisms and leukemia risk: a HuGE minireview. Am J Epidemiol 2003;157:571-582.

62 Sharp L, Little J: Polymorphisms in genes involved in folate metabolism and colorectal neoplasia: a HuGE review. Am J Epidemiol 2004;159:423-443. 